\title{
In-situ Investigation of the Fracture Behaviors of 2195-T8 Aluminum-Lithium alloy
}

\author{
Liang $\mathrm{WANG}^{1, \mathrm{a}}$, Min $\mathrm{HAO}^{1, \mathrm{~b}}$, Guoai $\mathrm{LI}^{1, \mathrm{c}}$ and Gaohong $\mathrm{CHEN}^{2, \mathrm{~d}}$ \\ ${ }^{1}$ Beijing Institute of Aeronautical Materials, Beijing 100095, China \\ ${ }^{2}$ Beijing Engineering Research Center for Advanced Aluminum Alloy, Beijing 100095, China \\ ${ }^{\mathrm{a}}$ wangliangisme@163.com ${ }^{1}$ \\ bhaomin00@163.com \\ ${ }^{\mathrm{c}}$ Lee ai@sina.com \\ dHong ChenG@163.com
}

\begin{abstract}
In this paper, the tensile crack initiation and propagation behavior of 2195-T8 Aluminum-Lithium alloy was studied by in situ scanning electron microscope observation at room temperature. It was found that cracks initiated at second phases which propagated along the grain boundaries only as $T_{1}$ phases could retard crack growth inside grains. With further increase of strain, within the grain a large number of slip bands were produced, resulting in the deflection of the grains, which leaded to transgranular fracture at last. SEM examination show both intergranular and transgranular fracture surface morphology indicating that the 2195-T8 alloy revealed a mix mechanism for the fracture.
\end{abstract}

\section{Introduction}

In the aeronautics and space industries, one of the most effective ways to reduce weight is to reduce the density of the aluminum alloys used. For purposes of reducing the alloy density, lithium additions have been used. 2195 Aluminum-Lithium alloy is widely used in aerospace and aeronautic fields for its light weight, high specific strength, good ductility and toughness [1-3]. The 2195 Aluminum-Lithium alloy is an Al-Cu-Mg-Li-Ag-Zr alloy, which is one of the"Weldalite" alloys [1]. These alloy contain a wide variety of precipitates, depending upon heat treatment conditions, including Guinier-Preston (GP) zones, $\beta^{\prime}\left(\mathrm{Al}_{3} \mathrm{Zr}\right), \delta^{\prime}\left(\mathrm{Al}_{3} \mathrm{Li}\right), \delta$ (AlLi), $\mathrm{T}_{1}\left(\mathrm{Al}_{2} \mathrm{CuLi}\right), \mathrm{S}^{\prime}$ and $\mathrm{S}\left(\mathrm{Al}_{2} \mathrm{CuMg}\right), \mathrm{T}_{2}\left(\mathrm{Al}_{6} \mathrm{CuLi}_{3}\right)$, and possibly $\Omega$ as well [4-7]. The 2195-T8 alloy was selected in this paper. The primary strengthening phase $T_{1}$ precipitates uniformly distributed [8-9]. The $\mathrm{T}_{1}$ precipitate phase acts as a non shearable barrier to hinder dislocation motion, and is considered to be responsible for the relatively good strength and fracture toughness properties of 2195-T8 when compared to other Al-Li alloys [10-11]. The precipitation of the $T_{1}$ phase in 2195-T8 will promote homogeneous slip, as opposed to other Al-Li alloys that exhibit localized slip mechanisms. This homogeneous deformation contributes to the increased strength and fracture toughness of this alloy [12].

In aluminum alloys, it is general that dimple type fracture occurs from inclusions or second phases particles. Intergranular, transgranular, local shear and delamination type

* Corresponding author: wangliangisme@163.com 
fractures are also sometimes observed [13-15]. Most of the investigations of 2195 Aluminum-Lithium alloy were focused on the weld and fatigue properties [16-17]. However, little data is available or has been published with regards to the tensile fracture behaviors of 2195-T8 alloy. The present work was performed on the 2195-T8 Aluminum-Lithium alloy hot rolled plate. The in-situ scanning electron microscope technique was used to investigate the evolution of the tensile crack initiation and propagation. The microstructure of the fracture surfaces is characterized in an effort to identify the fracture mechanism.

\section{Experimental}

Alloy AA2195 has the composition range (all in wt.\%) (3.7-4.3)Cu-(0.8-1.2)Li (0.25-0.8) Mg- $(0.1-0.5) \mathrm{Ag}-(0.04-0.18) \mathrm{Zr}$. It was provided as hot rolled plate in the T8 condition with a thickness of $5 \mathrm{~mm}$. The specimens for in-situ tensile tests were machined from the rolled plate with gauge length parallel to the transverse direction. The dimension of the specimen is shown in Fig. 1. The overall length of each sample was $45 \mathrm{~mm}$ with a gage length of $20 \mathrm{~mm}$ and thickness $0.7 \mathrm{~mm}$. The surfaces of all the specimens were polished and then etched in a solution of $1 \% \mathrm{HF}+1.5 \% \mathrm{HCl}+2.5 \% \mathrm{HNO}_{3}+95 \% \mathrm{H}_{2} \mathrm{O}$ to reveal the microstructure. The in-situ tensile tests were performed at room temperature in the vacuum chamber of the SEM using a specially designed servo-hydraulic testing system for fensile loading produced by SHIMADZU as SEM-SERVO 550.

Fracture surfaces of the failed specimens were examined in a JSM-7001F scanning electron microscope (SEM) to determine the predominant macroscopic fracture mode and to characterize the fine-scale topography and features on the fracture surface. Samples for SEM observation were obtained from the deformed specimens by sectioning parallel to the fracture surface.Specimens for transmission electron microscopy (TEM) were cored from transverse cross sections by electrodischarge machining. Slices cut from these cylinders were mechanically thinned to $100 \mathrm{~mm}$ and then electropolished in a solution of $30 \% \mathrm{HNO}_{3}$ $+70 \% \mathrm{CH}_{3} \mathrm{OH}$ at $15 \mathrm{~V}$ between $-30^{\circ} \mathrm{C}$ and $-20^{\circ} \mathrm{C}$. The TEM observations were conducted on JEOL-2100 TEM operated at $200 \mathrm{kV}$.



Fig. 1 Dimensions of in situ ten tension specimens ( $\mathrm{mm}$ in units).

\section{Results and Discussion}

Fig. 2 shows the microstructure of 2195-T8 aluminum-lithium alloy as tri-planar optical micrographs along the three orthogonal directions of the rolling direction (RD), transverse direction (TD) and normal direction (ND) respectively. Grains show typical elongation along the rolling direction. In the RD-TD plane, original large grains and small equiaxed recrystallized grains were observed in 2195 alloy, while there were large pancake-shaped grains with equiaxed recrystallized grains in the RD-ND and TD-ND planes. Meanwhile 
some relatively large constitutive particles (approximately $0.5-10 \mu \mathrm{m}$ ) were gathered in clusters along the rolling direction, which consisted mainly of $\mathrm{Cu}$-rich and $\mathrm{Fe}-\mathrm{Cu}$ intermetallics [18].


Fig. 2 Tri-planar optical micrographs of 2195-T8 aluminum alloy

Fig. 3 is TEM images of the 2195-T8 material with a corresponding SAED pattern of the Al [110] zone axis. The precipitateis characterized by selected area diffraction (SAD) (as shown in Fig. 3(a). The SAD result shows that the diffraction spots are from $T_{1}$ and $\delta^{\prime}$ phase. The Fig. 3(b) and (c) are the bright-field and dark field of $T_{1}$ precipitate recpectively. A high density of fine $T_{1}$ platelets is observed. The $T_{1}\left(\mathrm{Al}_{2} \mathrm{CuLi}\right)$ primary strengthening phase is reported to form after extended artificial aging $(>16 \mathrm{~h})$ [19]. $T_{1}$ phase is an equilibrium phase, which shows hexagonal flake or needle shape, about $100 \mathrm{~nm}$ in length, $1 \mathrm{~nm}$ in thickness, belonging to hexagonal $(\mathrm{a}=0.497 \mathrm{~nm}, \mathrm{c}=0.934 \mathrm{~nm})$. The $\mathrm{T}_{1}$ is a hexagonal crystal structure with (0001) $\mathrm{T}_{1} / /\{111\} \mathrm{Al}$ and (0101) $\mathrm{T}_{1} / /<110>\mathrm{Al}[20]$.

Besides, there also exist small amounts of $\delta^{\prime}$. The $\delta^{\prime}$ phase is an metastable phase, which shows spherical shape with about $10 \mathrm{~nm}$ in diameter, belonging to cubic system $(\mathrm{a}=0.401$ $\mathrm{nm}$ ). The Fig. 3(d) and (e) are the bright-field and dark field of $\delta^{\prime}$ precipitate recpectively.
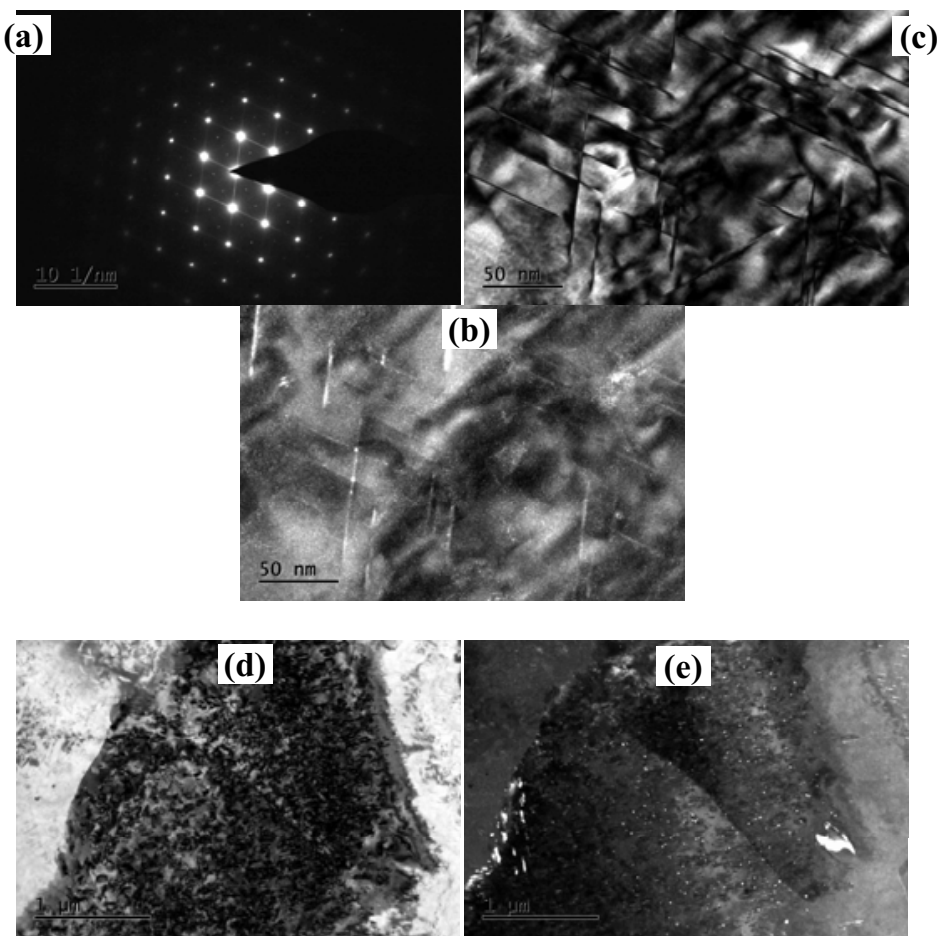
Fig. 3 Typical TEM images showing the distribution of the $T_{1}$ and $\delta^{\prime}$ precipitates of the 2195-T8 alloy, take along the [110] zone axis. (a) [110] zone axis SAD pattern, (b) bright-field and (c) dark field of $T_{1}$ precipitates, (d) bright-field and (e) dark field of $\delta^{\prime}$ precipitates

The tensile fracture behavior of 2195 aluminum at ambient temperature was investigated by using an SEM in situ observation method. The results are illustrated in Fig. 4. Fig. 4(a) plot the typical tensile flow curves for the 2195 alloy. Individual still images were obtained from the video capture during the tensile test from (A) to (H) are presented in Fig. 4(b)-(i). The yield strength of the 2195 aluminum sample was measured to be $540 \mathrm{MPa}$.

It can be seen from Fig. 4(b) and (c) that small cracks first initiate at the second phase particle when the strain is $6 \%$. The second phase particle, $10 \mu \mathrm{m}$ in length, is to be cut off by dislocations, and the sedimentation of the dislocation to the grain boundary is easy to pile up. The local shearing deformation is easily frequent, and there is the high possibility of separation and intergranular fracture in the slip plane.

As the strain increases, many voids nucleated at grain boundary are observed. Through their growth and linking each other, macro-voids and macro-cracks are formed, seen from in Fig. 4(d) and (e). Meaawhile, it was indicated that the coarse particles were debonded from the matrix materials (Fig. 4(e)).

As shown in Fig. 4(f), with the increase of deformation, the crack further propagated along the grain boundary, indicated intergranular failure. Besides, it can be observed that the micro-cracks caused by fracture of the particle itself or by debonding at the particle interface inside the grain did not propagate with the increasing deformation. It is considered that in this case, the main strengthening $T_{1}$ precipitates in the interior grain prevent the extension of the crack. Moreover, some slip traces were observed with an increase in load.

When the deformation reaches $85 \%$, many slip lines appeared, resulting in the rotation of the grain (Fig. 4(g)). Typical SEM images at low and high magnification corresponding to the point $G$ were presented in Fig. 4(h) and Fig. 4(i). It reveals that the loading leads to the aggravation of the slip and the coalescence of macrocracks. And ultimately, results in transgranular shear failure.

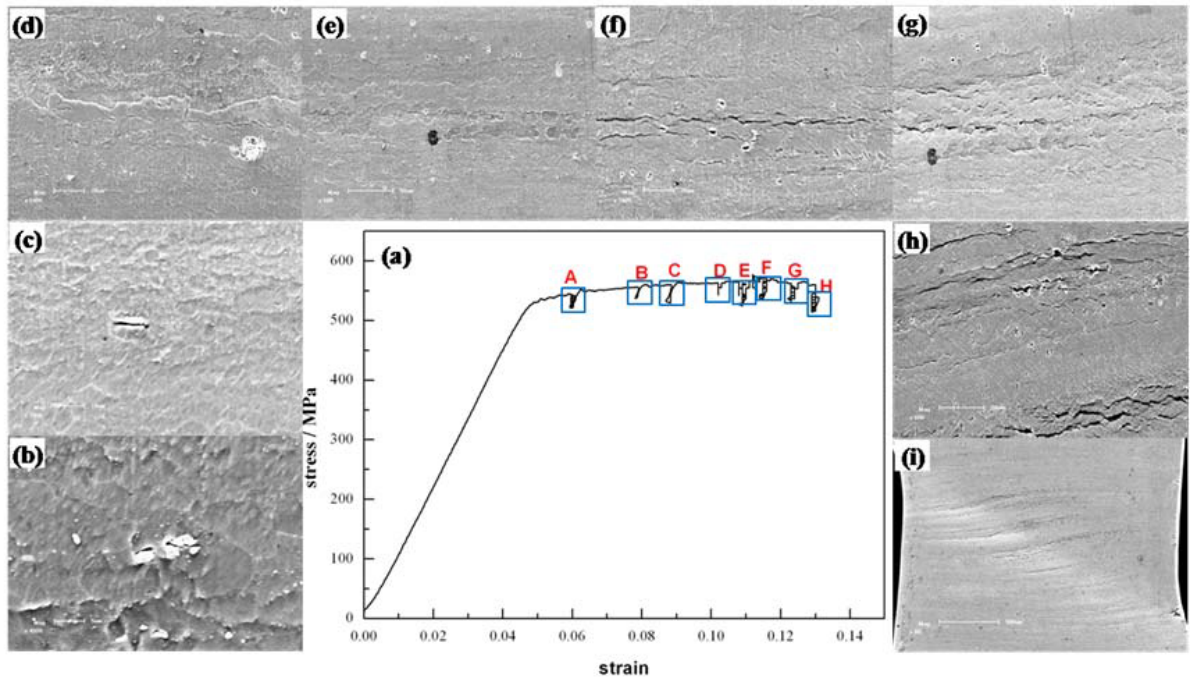

Fig. 4 Results from in situ tension testing of the 2195-T8 alloy, (a) the typical tensile flow curves and (b), (c), (d), (e), (f), (g), (h), (i) the SEM images corresponding to from (A) to (H) shown on the stress strain curves. 
After mechanical testing, SEM examination of the surface of the samples was performed and is presented in Fig. 5. In general, one main crack appears, making an angle of $45^{\circ} \pm 10^{\circ}$ with the tensile axis (Fig. 5(a)).

As shown in Fig. 5(b) and (c), at the microscopic scale the fracture surface was really rough. High magnification observation of the fracture surface revealed predominately transgranular shear failure. Meanwhile, layering intergranular fracture and secondary cracking were observed in Fig. 5(d). Also, the fracture surface appears a small amount dimples, having different sizes and illustrates the ductile nature of the failure shown in Fig. 5(e).

Fig. 6 shows the process of the tensile fracture of 2195-T8 alloy. Based on the above results, cracks first initiated at the intracrystalline and intergranular second phase particles by decohesion between second phase and Al matrix. With the increase of the deformation, many voids nucleated at the grain boundary and propagated along the grain boundary. Meanwhile, cracks initiated inside grains were not propagating because of the retard of $T_{1}$ phase which is the main strengthening phase of 2195-T8 alloy. With further increase of strain, within the grain a large number of slip bands were produced, resulting in the deflection of the grains. The material showed clear evidence of planar slip activity, with shear regions exhibiting a linear, relatively crystallographic appearance. We interpret these features that 2195-T8 alloy possess high stacking fault energies as the deformation increasing. Plastic deformation is accommodated by dislocation slip, in accordance with the above discussion. And ultimately, results in transgranular shear failure. So it can be concluded that the 2195-T8 alloy revealed a mix mechanism for the fracture, and both intergranular and transgranular fracture surface morphology were observed under the SEM examination.

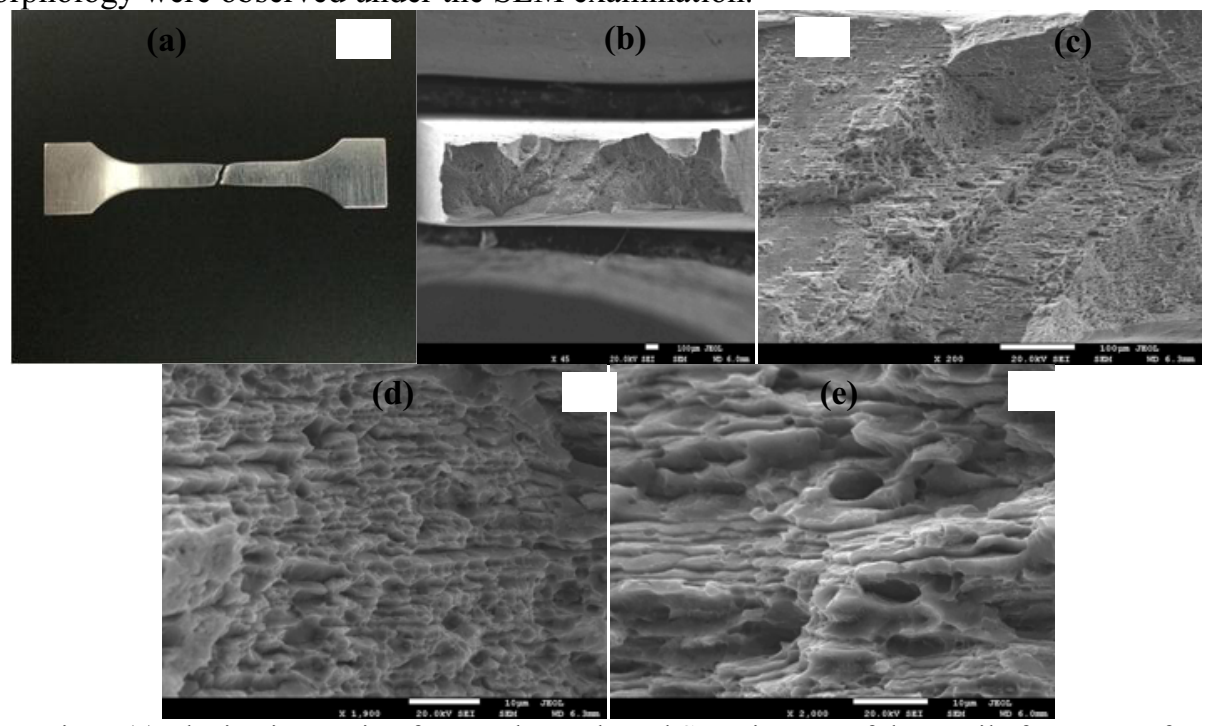

Fig. 5 (a) The in-situ tension fractured sample and SEM images of the tensile fracture surface of the 2195-T8 alloy: (b) overall morphology, (c) low magnification of the fracture surface, (d) and (e) high magnification of the fracture surface.

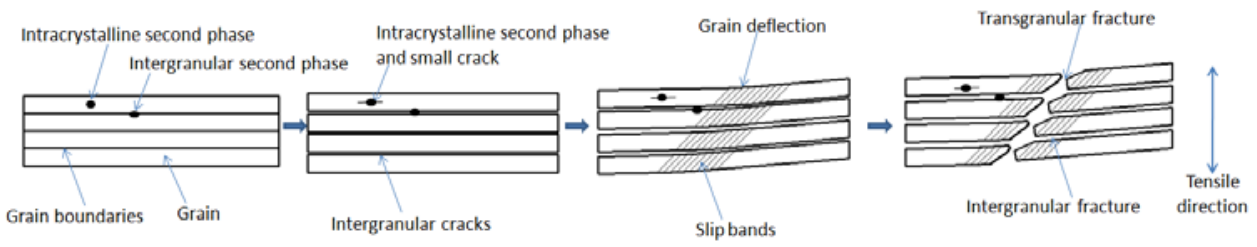

Fig. 6 Schematic diagram of the tensile fracture process 


\section{Summary}

In summary, the in-situ tensile tests were performed on hot rolled 2195-T8 Aluminum-Lithium alloy. The in-situ SEM investigation and the SEM investigation of the tensile fracture surface were used to investigate the evolution of the tensile crack initiation and propagation, in an effort to identify the fracture mechanism. The following results can be drawn: strengthening precipitates $\delta^{\prime}$ phase and $T_{1}$ phase are observed, and $T_{1}$ phases could retard crack growth inside the grains, which leaded cracks to grow along the grain boundaries. Lots of slip bands were developed inside grains with the increase of deformation, which leaded to ductile transgranular fracture at last. So both intergranular and transgranular fracture surface morphology were observed under the SEM examination.

\section{Acknowledgements}

This work was financially supported by the National Natural Science Foundation of China (51374187, 51474195).

\section{References}

1. T. J. Langan and J. R. Pickens, in: Aluminum-Lithium Alloys (Proc. of the Fifth Znt. AI-Li Conf), edited by T. H. Sanders and E. A. Starke. MCE Publications Ltd., Birmingham, U.K. (1989).

2. K. S. Kumar, S. A. Brown and J. R. Pickens: Scripta metall. mater. Vol. 24 (1990), p. 1245 .

3. I. Sinclair, P. J. Gregson: Scripta Metall. Mater. Vol. 30 (1994), p. 1287.

4. K. S. Kumar, S. A. Brown and J. R. Pickens: Acta mater. Vol. 44 (1996), p. 1899.

5. $\quad$ K. S. Kumar and F. H. Heubau: Acta mater. Vol. 45 (1997), p. 2317.

6. R.W. Fonda, J.F. Bingert and K.J. Colligan: Scr. Mater. Vol. 51(2004), p. 243.

7. P. Cavaliere, M. Cabibbo, F. Panella and A. Squillace: Mater. Des. Vol. 30 (2009), p. 3622.

8. J. A. Schneider, A. C. Nunes JR, P. S. Chen and G. Steele: J. Mater. Sci.Vol. 40 (2005), p. 4341.

9. A. K. Shukla and W.A. Baeslack, III: Scr. Mater. Vol. 56(2007), p. 513.

10. P.M.G.P. Moreira, A.M.P. de Jesus, M.A.V. de Figueiredo, M. Windisch, G. Sinnema and P.M.S.T. de Castro: Theoretical and Applied Fracture Mechanics Vol. 60 (2012), p. 1 .

11. H. L. Qin, H. Zhang and H. Q. Wu: Mater.Sci.Eng.A Vol. 626 (2015), p. 322.

12. D. F. Metz, E. R. Weishaupt, M. E. Barkey and B. S. Fairbee: Journal of Engineering Materials and Technology Vol. 134 (2012), p. 021005-1.

13. T. Kobayashi: Mater.Sci.Eng.A Vol. 286 (2000), p. 333.

14. And. Öchsner, Wer. Winter and Gün. Kuhn: Advanced engineering materials Vol. 2 (2000), p. 423.

15. B. Decreus, A. Deschamps, P. Donnadieu and J. C. Ehrström: Mater.Sci.Eng.A Vol. 586 (2013), p. 418.

16. D.L. Chen and M. C. Chaturvedi: Metallurgical and Materials Transactions A Vol. 83-87 (2001), p. 2729.

17. D.F. Metz and M.E. Barkey: International Journal of Fatigue Vol. 43 (2012), p. 178.

18. Y. X. Du, X. M. Zhang, L. Y. Ye, and Z. H. Luo: Tran Mater Heat Treat Vol. 27 (2006), p. 52. (in Chinese)

19. H. L. Qin, H. Zhang, and H. Q. Wu: Mater.Sci.Eng.A Vol. 626 (2015), p. 322.

20. T. Dorin, F. D. Geuser, W. Lefebvre, C. Sigli and A.Deschamps: Mater.Sci.Eng.A Vol. 605 (2014), p. 119. 